\title{
The Appraisal Model of Teenagers' Landscape Preference based on Demographic and Personality Characteristics
}

\author{
Sima Alizadeh ${ }^{1 *}$, Minoo Sadeghi ${ }^{2}$, Aldrin Abdullah $^{3}$ \\ ${ }^{1}$ Faculty of Built Environment, University of New South Wales, Sydney, Australia \\ ${ }^{2}$ Professional Consultation Centre of Mandegar, Isfahan, Iran \\ ${ }^{3}$ School of Housing, Building and Planning, Universiti Sains Malaysia, Penang, Malaysia \\ *s.alizadeh@student.unsw.edu.my
}

Received : 24 November 2017 Final Version Received: 23 January 2018

\begin{abstract}
Landscape design has attracted researchers' attention due to a significant attachment between landscape and society. It is therefore necessary that landscape is designed based on people's preferences. Thus, it is imperative that people's landscape preference and the relevant influential factors to be identified. This research aims to introduce a model to provide the best prediction for landscape preference based on demographic and personality characteristics among 384 teenagers in Isfahan, Iran. Accordingly, the research follows three objectives to predict teenagers' preference for mountain, forest, and agricultural landscapes. Cattell Sixteen Personality Factor Questionnaire was conducted to examine respondents' personality characteristics. Participants' landscape preferences were measured by using a visual preference survey. In this survey respondents rated pictures of three kinds of landscape including mountain, forest, and agricultural landscapes. The results revealed that in prediction of teenagers' landscape preference, the factors of creativity, field of study, and gender are influential. The findings raise implications for the concerned architects and environmental designers as well as planners and decision makers in both ecological and psychological settings.
\end{abstract}

Keywords: Landscape Type, Personally Traits, Visual Perception, High School, Iran.

\section{INTRODUCTION}

Landscape is defined as a portion of land where people begin to explore its benefits, build their lives on it, bear its consequences, and appreciate its pleasure each day. Indeed, landscape defines and describes people as a society; and like home which is closely linked to a person's characteristic and self-expression, landscape is an essential and dynamic environment. Landscapes, unconsciously, surround individuals and their everyday lives unceasingly, insofar as people extend an emotional relationship to it. As a result, widespread academic research has been done in order to determine the aspects that contribute to individuals' interest for landscapes (Sevenant \& Antrop, 2006).

However, modern landscape design disregards this deep connection between people and landscape (Augé, 1995; Relph, 1976). Indeed, the attention of contemporary landscapes is paid to visual characteristics and environmental aspects associated with sceneries. In the meantime, very few investigations have considered the feelings and interest of persons living within those landscapes; while, this is necessary that in building and growing landscapes, individuals' preferences and desires are considered. Accordingly, gaining deep insight into which landscape people prefer is considered vital.

Literature contains several studies on the contribution of various factors towards landscape preference. In the setting of demographic factors, during an investigation in Norway, Strumse (1996) found a significant difference in landscape preference between gender groups. He stressed that women revealed more positive attitudes to natural environments in comparison with men. In this regard, it was found that men prefer rough and mountainous landscapes more than women (Sonnenfeld, 
1969). Nonetheless, in another investigation, the influence of gender factor was not influential in almost all the examined types of landscape (Yu, 1995). Similarly, Purcell, Peron, and Berto (2001) found that males $(\mathrm{N}=50)$ and females $(\mathrm{N}=50)$ at the university of Italy are not significantly different in preference for landscape.

With respect to people's differences in landscape preference based on their education level, Yu (1995) reported that education level (associated with age) is a powerful determinant factor towards landscape preference. Moreover, during a research on 642 residents in Belgium with primary to post-academic education, Sevenant and Antrop (2010) found that individuals who care more about naturalness are possibly among low-educated people. Likewise, the results of an investigation into landscapes of forest, roughness, cultivation, and wetness in Netherlands indicated that interest for cultivated landscape is more negative for academics than for non-academics ( $\mathrm{r}=-0.48)$ (Van den Berg, Vlek, \& Coeterier, 1998). It was also found that low-educated people disclose lower interest in wilderness and vice versa (Van den Berg \& Koole, 2006). Herein, among three studied landscapes of townscape, farmland, and forest, Harris Jr. (2009) found only preference for farmland is significant across education. On the contrary, during an investigation on a sample of Canadian citizens $(\mathrm{N}=90)$, Dearden (1984) showed that there is no significant difference in landscape preference based on education level.

Concerning the subject of landscape preference, a few researches inspected the contribution of expertise towards individuals' gradings for landscapes. In an investigation on 104 students of psychology courses and 94 students of landscape-related fields in Norway, Strumse (1996) showed that expertise is a significant factor on visual perception for farming scenes. Furthermore, Stamps (1999) provided an evidence on difference between designers and non-designers in preference for landscapes. On the contrary, Yu (1995) found no significant difference in landscape preference between nonexperts with three expert groups of landscape architectures, landscape designers, and landscape horticulturists in China. Likewise, Dearden (1984) concluded that there is no significant difference in landscape preference between professionals in the field of Urban Planning and other people.

Concerning the issue of people's attitude towards landscape from different geographical locations, Chen, $\mathrm{Xu}$, and Devereux (2016) conducted a survey in two cities of Cambridge and Nanjing in UK and China $(\mathrm{N}=180)$. The results indicated that the respondents' rating for freely growing trees, diverse design of green environments, and separate houses was similar in both cities. The results also showed that the influence of age and education is greater than gender and major. It is also debated that sense of place attachment is important to people's environmental behaviour and interest for landscape (Ardoin, 2014). In this regard a study on the association between social perceptions and landscape multi-functionality suggested that place attachment is highly influential on people's level of support for landscape conservation (García-Llorente et al., 2012).

Research on the contribution of personality towards people's rating for landscapes has been conducted in a few studies. In this view, Maciá (1979) measured five personality traits of paranoia, control, sincerity, extraversion, and amount of doubts among 226 university students of the Arts in Spain. He found that respondents' choices of landscapes are different based on their personalities. The findings revealed that respondents who scored high in emotional control were interested in pleasant (not cold and dry) landscapes. Subsequently, Egan and Stelmack (2003) showed that mountain climbers and people who are interested in mountainous landscape possibly achieve higher scores in extraversion trait. Correspondingly, in a study on 128 Spanish university students, Abello and Bernaldez (1986) showed that less emotionally stable people are interested in landscapes with recurrent patterns and structural rhythms. Also, persons with high scores in sense of responsibility showed no interest in wintery, defoliated, and hostile landscapes. Moreover, it was found that students who prefer agriculture are most likely to be less creative (Bergum \& Cooper, 1977).

Based on the literature of landscape preference, it was perceived that a considerable amount of investigations have been conducted to examine the contributions of socio-cultural, socioeconomic, and people's background factors towards landscape preference (Sevenant \& Antrop, 2010). However, the influence of individuals' personality characteristics on their landscape preferences has far less been investigated. Furthermore, personality characteristics are quite broad and varied (Jin \& Yongyu, 2007) but the prior researches have covered only a few of them. Thus, it is necessary to conduct more studies in this scope. 
In addition, most of previous investigations into people's differences in landscape preference put a great emphasis on studying adults and university students (e.g., Buijs, Elands, \& Langers, 2009; Crow, Brown, \& De Young, 2006; Dearden, 1984; Harris Jr., 2009; Sevenant \& Antrop, 2010; Strumse, 1996; Winkel, Malek, \& Thiel, 1969). However, very few investigations have been conducted on a sample of teenagers and school children (e.g., Zube, Pitt, \& Evans, 1983); while based on cognitive development theory, teenagers have different preferences and perceptions from adults (Piaget, 1964; Saif, 1996; Short \& Rosenthal, 2003).

Lastly, most studies on landscape preference were conducted in American and European countries with western culture. By contrast, very few investigations in this scope have been conducted in Asian countries. Therefore, the related literature is still limited in terms of differences in cultural setting as well. In particular, no study into this issue has been conducted in Iran so far.

Consequently, to bridge up theses gaps, this research attempts to explore a model to present the best prediction for landscape preference based on demographic and personality characteristics of high school teenagers in Isfahan City, Iran.

For this purpose, the present research focuses on measuring three personality characteristics of extraversion, intelligence, and creativity. According to Cattell (Schultz \& Schultz, 1994), extraversion, intelligence, and creativity are all categorized as 'common traits' and 'source traits'. Common traits are those that exist in each person to some extent. Therefore, the sample population of the study may be broadened to a bigger population in terms of personality characteristics. Source traits are the traits that apparently have a true structural effect on personality which are also stable and permanent traits. So, the outcomes of this study would be reliable and inalterable.

Accordingly, with respect to the overall aim of this study, the specific research objectives are addressed as follows:

- To provide a model to predict teenagers' preference for mountain landscape based on their demographic and personality characteristics.

- To provide a model to predict teenagers' preference for forest landscape based on their demographic and personality characteristics.
- To provide a model to predict teenagers' preference for agricultural landscape based on their demographic and personality characteristics.

\section{MATERIALS AND METHODS}

The present study is a descriptive form of survey study. Quantitative method was adopted to collect data. As the independent variables, this research measured demographic characteristics (gender, level of education, and academic field of study) together with personality characteristics (extraversion, intelligence, and creativity). The research dependent variables include preferences towards mountain (figure 1), forest (figure 2), and agricultural (figure 3) landscapes.

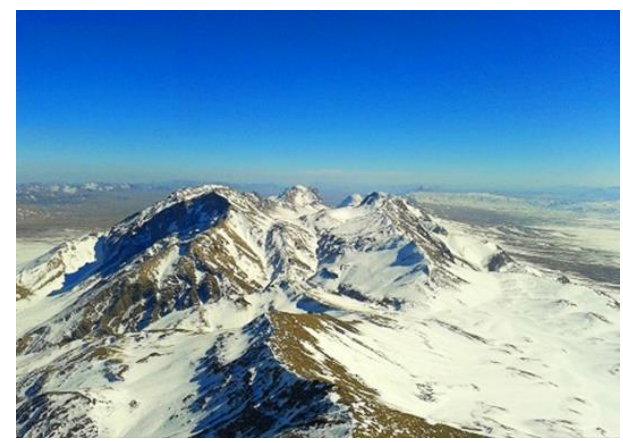

Figure 1: Mountain landscape (http://www.fereydanna.ir)

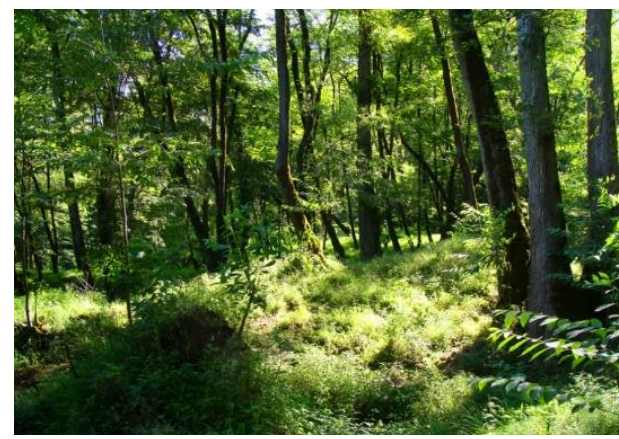

Figure 2: Forest landscape (Alizadeh, 2013)

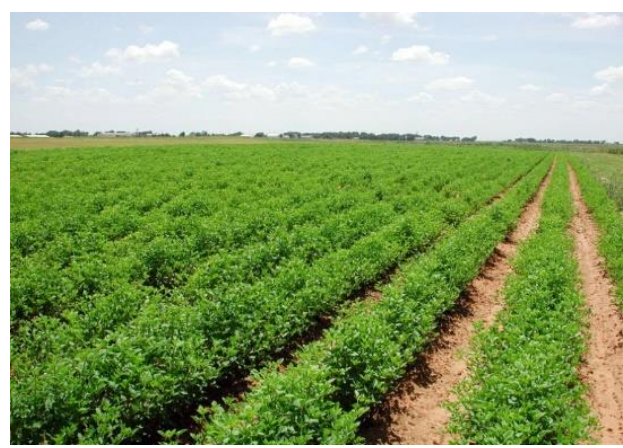

Figure 3: Agricultural landscape (http://www.kermanfarda.com) 


\subsection{STUDY AREA}

The study area of this research is Isfahan City, Iran (Figure 4). The city is geographically located in the centre of the country. Due to its thousands year of antiquity and history, together with pristine natural regions, Isfahan is popularly known as Half of the World (IRNA, 2010). Isfahan is covered with mountainous regions and forests together with farmland areas (Justice Ministry of Isfahan, 2008). The diversity of landscape types in Isfahan (mountain, forest, and agricultural landscapes) which suits the aim of this study encourages the researchers to choose this city as the area of study.

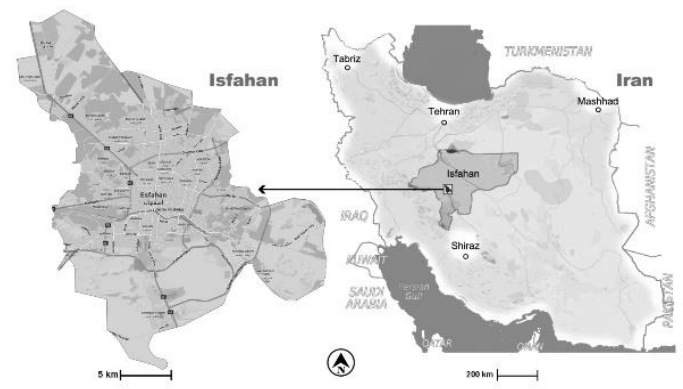

Figure 4: Map of Isfahan as the area of study

\subsection{RESEARCH SAMPLE}

This study targets high school teenagers in Isfahan City, Iran as its population. The sample consisted of 384 volunteer high school teenagers (192 girls and 192 boys) with the mean age of 16.3 years old (between 15 to 18 years old). To determine the sample size, Krejcie and Morgan's (1970) table of sample size was used.

The research samples were determined based on stratified and systematic random sampling techniques. Through stratified technique, high school teenagers from different parts of Isfahan City had the opportunity to take part in the research so that the results of this research can reflect the whole population. Consequently, this research exploited the geographical breakdown of the city which was made by the Education Department of Isfahan (2013). In this aspect, the city is geographically divided into six areas of District 1, District 2, District 3, District 4, District 5, and District 6 (Figure 5). Therefore, the samples were collected from all the mentioned districts of Isfahan for examination.

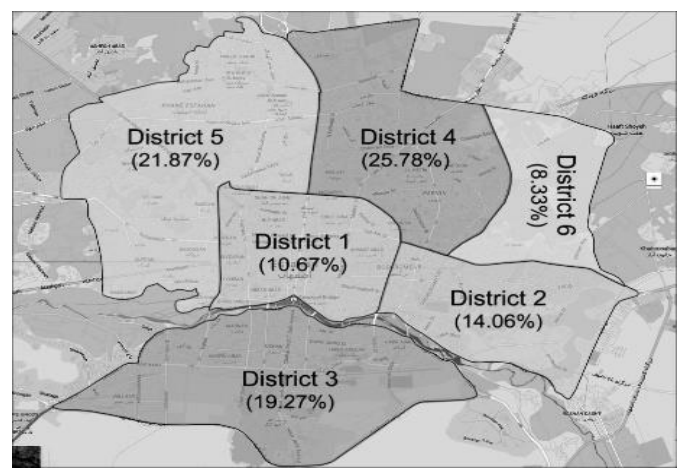

Figure 5: Breakdown of Isfahan city in terms of education districts and percentage of sample taken from each district

The systematic random sampling technique was later applied to select the sample in accordance with respondents' gender, level of education, and field of study with an almost equal number at each stratum.

There are four academic levels at high school in Iran categorized into the grades of 1, 2, 3, and 4 . High school grade-one students in Iran are normally under general education training; however, from grade two onwards, they must select their specific academic discipline of study and follow professional training of their chosen field. Four general fields of study are offered at high school level in Iran, including Mathematics, Experimental Sciences, Humanities, and the Arts. As a result, in this research, four levels of education, including grade one, grade two, grade three, and grade four of high school were studied as the factor of education level. Also, four academic fields of study, including Mathematics, Experimental Sciences, Humanities, and the Arts in line with general education were examined (Figure 6).

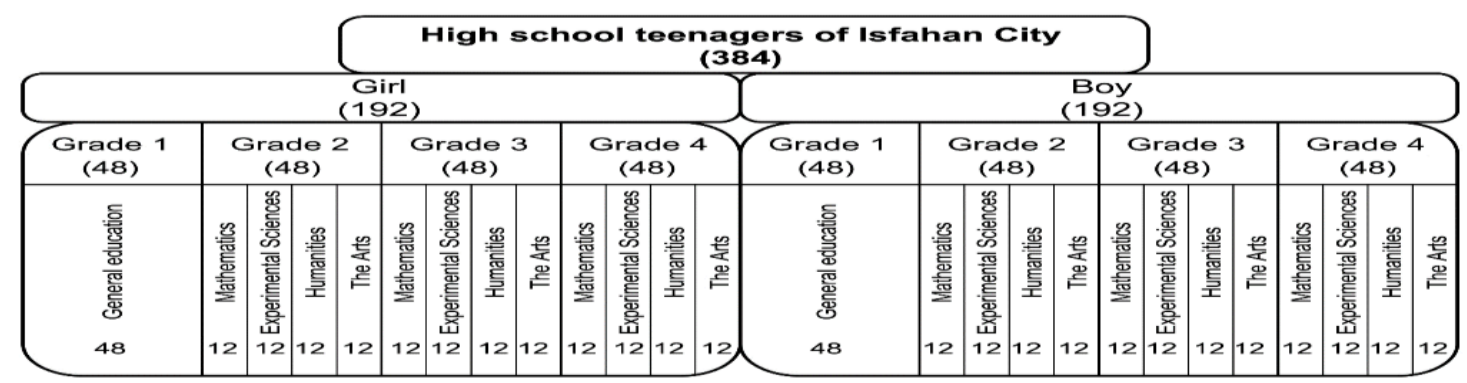

Figure 6: Stratification of the sample based on demographic characteristics (gender, level of education, and field of study) 


\subsection{INSTRUMENTS}

For the purpose of data collection, three questionnaires were conducted. Demographic questionnaire was used to indicate the respondents' three demographic characteristics of gender, level of education, and academic field of study.

Cattell Sixteen Personality Factor Questionnaire (16PF) (1956) was employed to evaluate the respondents' three personality characteristics, including extraversion, intelligence, and creativity. In Iran, Barzegar (1996) translated, adapted, and standardized the 16PF Questionnaire into Persian (the language spoken in Iran). He reported that the Persian version of the scale is highly valid and reliable (Asghari, 2001).

Lastly, to examine the respondents' landscape preference, visual preference survey was conducted. The respondents were asked to rank 15 pictures of three landscape types in the form of colour slides on a 7-point Likert scale. In this Likert scale point 1 and point 7 are respectively referred to the least and the most preferred landscapes. The slides projected in a random order and comprised five pictures for each landscape type, including mountain, forest, and agricultural landscapes. The reliability coefficient of the visual preference survey was measured by Cronbach's alpha. The value indicated that the instrument is averagely 0.84 reliable. The instrument validity was also affirmed through three landscape architects and ecological experts in Iran.

\section{ANALYSES AND RESULTS}

Multiple Regression Analysis (stepwise method) was employed to examine the prediction of landscape preference variance through the independent variables. Before performing Multiple Regression Analysis, four preassumptions of regression analysis (multicollinearity, normality, outliers, and standardized residual analysis) were examined.

Since level of education and field of study are categorical variables with more than two categories, they were turned into dummy variables before being entered into the regression analysis, which was done by applying dummy coding process.

\subsection{RESULT 1}

The regression estimations revealed that creativity, Mathematics field of study, and gender variable can predict up to $7 \%\left(\mathrm{R}^{2}=0.070\right)$ of the variance of preference for mountain landscape (Table 1).

Table 1: Multiple Regression Analysis of Preference for Mountain Landscape

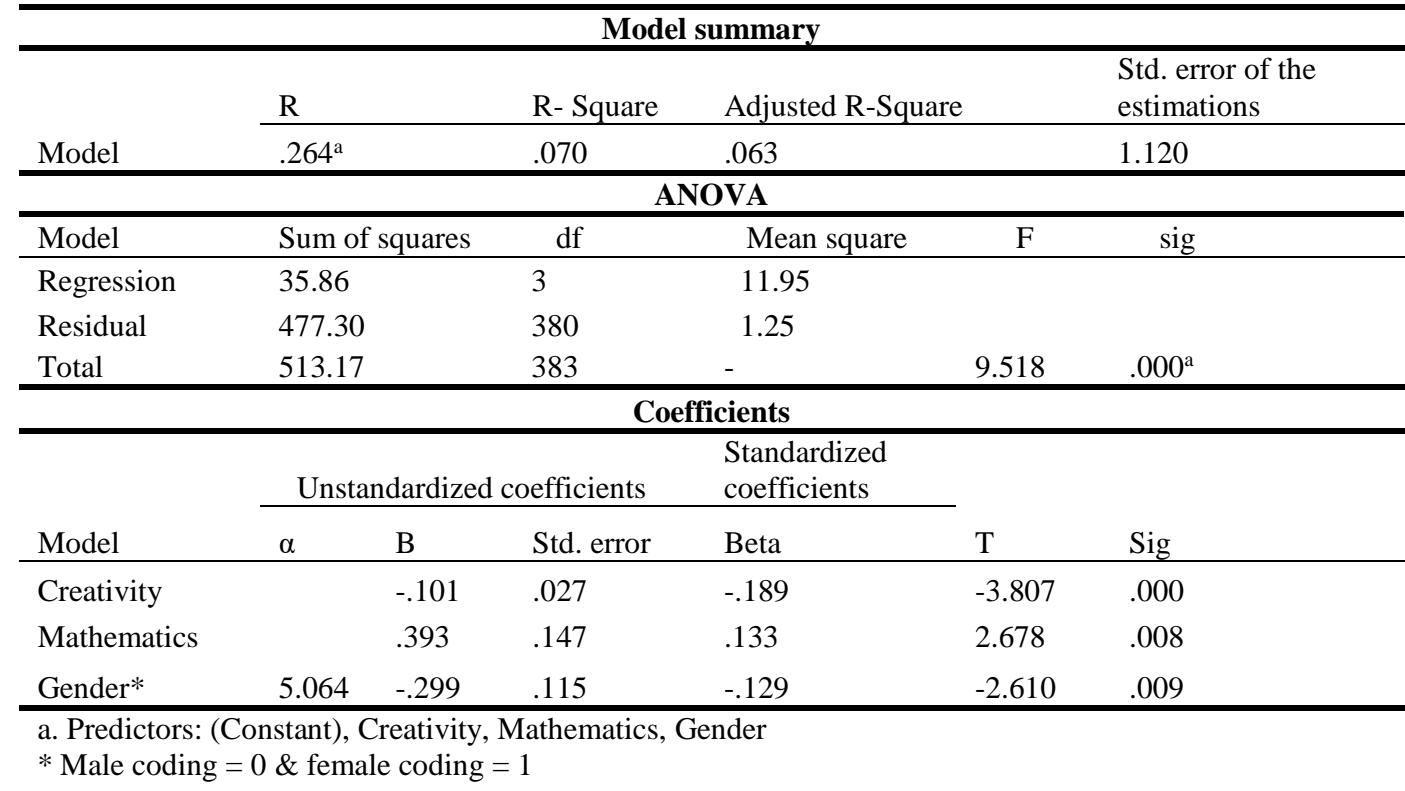

Among the remained factors in the regression model, creativity is the most powerful variable in prediction of the variance of preference for mountain landscape while gender reveals the least effect.
Based on the outcomes, creativity negatively correlates with preference for mountain landscape. This indicates that more creative teenagers had less preference for mountain landscape. Furthermore, respondents who 
studied Mathematics showed a stronger interest for mountain landscape than those of other fields of study. Moreover, mountain landscape was preferred more to boys than girls.
According to the regression analysis, Humanities and the Arts fields of study can predict up to $4.3 \%\left(\mathrm{R}^{2}=0.043\right)$ of the variance of preference for forest landscape (Table 2).

\subsection{RESULT 2}

Table 2: Multiple Regression Analysis of Preference for Forest Landscape

\begin{tabular}{|c|c|c|c|c|c|c|}
\hline \multicolumn{7}{|c|}{ Model summary } \\
\hline \multirow[b]{2}{*}{ Model } & \multicolumn{2}{|l|}{$\mathrm{R}$} & R-Square & \multicolumn{2}{|l|}{ Adjusted R-Square } & $\begin{array}{l}\text { Std. error of the } \\
\text { estimations }\end{array}$ \\
\hline & \multicolumn{2}{|l|}{$.209^{\mathrm{a}}$} & .043 & \multicolumn{2}{|l|}{.038} & .799 \\
\hline \multicolumn{7}{|c|}{ ANOVA } \\
\hline Model & \multicolumn{2}{|c|}{ Sum of squares } & $\mathrm{df}$ & Mean square & $\mathrm{F}$ & sig \\
\hline Regression & \multicolumn{2}{|c|}{11.08} & 2 & 5.541 & & \\
\hline Residual & \multicolumn{2}{|l|}{243.71} & 381 & .640 & & \\
\hline Total & \multicolumn{2}{|l|}{254.79} & 383 & - & 8.662 & $.000^{\mathrm{a}}$ \\
\hline \multicolumn{7}{|c|}{ Coefficients } \\
\hline & \multicolumn{3}{|c|}{ Unstandardized coefficients } & $\begin{array}{l}\begin{array}{l}\text { Standardized } \\
\text { coefficients }\end{array} \\
\end{array}$ & & \\
\hline Model & $\alpha$ & $\mathrm{B}$ & Std. error & Beta & $\mathrm{T}$ & Sig \\
\hline Humanities & & -.306 & .107 & -.147 & 2.851 & .005 \\
\hline The Arts & 6.309 & .246 & .107 & .118 & 2.293 & .022 \\
\hline
\end{tabular}

Among the remained factors in the regression model, Humanities field of study is the best predictor of the variance of preference for forest landscape. This shows that participants who studied Humanities field had the least preference towards forest landscape. Moreover, the outcomes indicated that those who study the Arts are more interested in forest landscape.

\subsection{RESULT 3}

Based on regression estimations, creativity variable can predict up to $1.4 \%\left(\mathrm{R}^{2}=0.014\right)$ of the variance of preference for agricultural landscape (Table 3).

Table 3: Multiple Regression Analysis of Preference for Agricultural Landscape

\begin{tabular}{|c|c|c|c|c|c|}
\hline \multicolumn{6}{|c|}{ Model summary } \\
\hline & $\mathrm{R}$ & R-Square & Adjusted R-Square & & $\begin{array}{l}\text { Std. error of the } \\
\text { estimations }\end{array}$ \\
\hline Model & $.119^{\mathrm{a}}$ & .014 & .012 & & 1.166 \\
\hline \multicolumn{6}{|c|}{ ANOVA } \\
\hline Model & Sum of squares & df & Mean square & $\mathrm{F}$ & sig \\
\hline Regression & 7.46 & 1 & 7.46 & & \\
\hline Residual & 519.32 & 382 & 1.35 & & \\
\hline Total & 526.78 & 383 & & 5.491 & $.020^{\mathrm{a}}$ \\
\hline \multicolumn{6}{|c|}{ Coefficients } \\
\hline & \multicolumn{2}{|c|}{ Unstandardized coefficients } & $\begin{array}{l}\text { Standardized } \\
\text { coefficients }\end{array}$ & & \\
\hline Model & $\mathrm{B}$ & Std. error & Beta & $\mathrm{T}$ & Sig \\
\hline Creativity & 5.461 & .028 & -.119 & -2.34 & .020 \\
\hline
\end{tabular}


The results indicated that creativity is negatively correlated with preference for agricultural landscape which means less creative teenagers showed more preference for agricultural landscape.

\section{DISCUSSION}

With respect to the results of Multiple Regression Analysis, teenagers' preferences for mountain, forest, and agricultural landscapes can be predicted through their demographic (gender and field of study) and personality (creativity) characteristics. In the following sections the three examined landscape types are deliberated individually.

\subsection{MOUNTAIN LANDSCAPE}

It was found that for prediction of mountain landscape preference, the contribution of creativity, Mathematics field of study, and gender can create the best model (Figure 7). Meanwhile, creativity and gender respectively revealed the largest and the smallest ratios in the prediction of preference for this landscape.

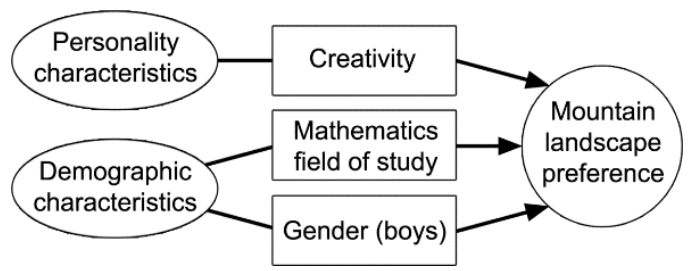

Figure 7: The appraisal model of preference for mountain landscape

Indeed, less creative people preferred mountain landscape which can be explained through sensitive characteristic of creative people (Cattell \& Mead, 2008) who may prefer smooth and round shapes rather than straight and rough forms with sharp angles like cliffs and mountainous sceneries.

The results also showed that teenagers who study Mathematics field positively reserve a preference for mountain landscape. It is true that preferences and perceptions of artists may differ from mathematicians. In contrast with mathematicians who are mostly in favour of straight solid forms such as mountains in nature, artists may be more interested in soft and flexuous shapes. Therefore, it would be expected that unlike creative people (like artists) who were not interested in mountain landscape, those who studied Mathematics show preference for this landscape.

Moreover, boys showed a great interest in mountain landscape. In literature, mountain is the sign of solidity, strength, and stability (Seaward, 2005). This interpretation of the concept of mountain corresponds with the analysis of men's individualities that characterise by Hanash (2008) and Maciá (1979). These researchers showed that in comparison with females, males are stronger, more stable, and tougher. As a result, it is anticipated that boys would show a greater preference for mountain landscape which is more suited to their characteristics. Consistent with this result, Sonnenfeld (1969) also agreed that males are more likely to be in favour of rough and mountainous landscapes in comparison with females.

Consequently, it was anticipated that creativity factor, Mathematics field of study, and gender (boys) would form an appropriate predictor model of preference for mountain landscape.

\subsection{FOREST LANDSCAPE}

Findings of the current research demonstrated that Humanities and the Arts fields of study can create the strongest model in the prediction of preference for forest landscape (Figure 8).

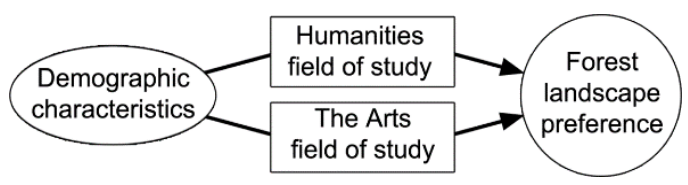

Figure 8: The appraisal model of preference for forest landscape

Based on the findings, participants who studied Humanities field showed less preference towards forest landscape. Meanwhile, those who studied the Arts were mostly interested in this landscape.

Correspondingly, Strumse (1996) found that students of the Arts fields and Humanitiesrelated fields have a significant difference in their preferences for landscapes. Likewise, Stamps (1999) found that there is a significant difference between designers' and nondesigners' choice of natural landscapes.

Indeed, it is asserted that people's academic discipline and major affect their beliefs or attitudes toward landscape (Baron \& Kenny, 1986). In this regard, Zheng, Zhang, and Chen (2011) showed that students of social science major (a branch of Humanities field of study) are less likely to be in favour of wilderness areas and forest environments (natural landscapes with no human intervention). Instead, they showed more preference for neat, clean, and well-maintained landscapes (landscapes with human intervention). 


\subsection{AGRICULTURAL LANDSCAPE}

The outcomes showed that among the tested independent variables only creativity can weakly contribute to the model of prediction for preference towards agricultural landscape (Figure 9).

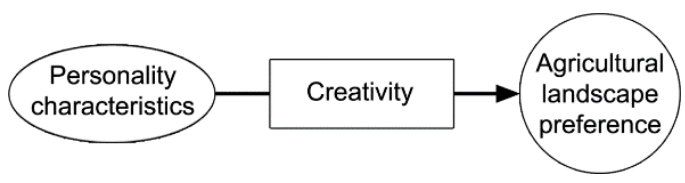

Figure 9: The appraisal model of preference for agricultural landscape

Based on the findings, less creative teenagers reserved more preference for agricultural landscape. One probable reason for this finding might be that agricultural landscape which is simple, open, plain, less-detailed, and not complicated can be preferable to less creative people whose characteristics are more compatible with this type of landscape. While creative people might be more interested in sophisticated, busy and detailed scenes. This result is in agreement with the findings of a research conducted by Bergum and Cooper (1977).

Considering that introversion is one of the features of creativity (Hurlock, 1974), the findings of an investigation done by Johnson and Feldman (2013) would then be consistent with the results of the present study. As introverted people are high in arousal level (Eysenck, 1990), Johnson and Feldman (2013) showed that preference for open areas and overviews (such as agricultural landscapes) is negatively correlated with introversion (a feature of creativity). They also provided reasons that creative individuals (with the aspects of openness to experience, motivated toward exploration, liking for sophistication) would not be in favour of open and vast prospects (like farming lands).

\section{CONCLUSION}

The results highlighted the influence of demographic and personality characteristics on landscape preference. It is worth mentioning that among the tested variables, field of study and creativity respectively had the strongest contributions towards teenagers' landscape preference. In the meantime, level of education, extraversion, and intelligence revealed no influence on teenagers' choice of landscape.

\section{$5.1 \quad$ LIMITATIONS RECOMMENDATIONS}

The topography of Iran comprises highlands and mountainous areas, forests, farmlands and agricultures, desert plains and lowlands, wetland and shores, and urbanized areas (Rajabi, 2008). However, due to the broadness of landscape types in Iran, merely three types of landscapes (mountain, forest, and agricultural landscapes) were investigated in this research. Thus, more studies on the scope of other landscape types in Iran are required.

In this investigation, preference for landscapes was studied by people's viewing landscape images instead of being physically on the site and viewing the actual landscape environment. Hence, it is recommended some future studies should focus on site landscape assessment. This means that people's landscape preference should be assessed by respondents observing the real landscape environment in which they can combine their different senses like touch, smell, and sound together with their vision sense.

Furthermore, the effect of season on landscapes should be considered. This study merely examined photographs of landscapes taken in summer. Therefore, it is suggested that seasonal changes on landscape should be considered in subsequent research. It is also recommended that some in depth research should be conducted on the reasons of people's preference for specific landscape type.

\section{REFERENCES}

Abello, R. P., \& Bernaldez, F. G. (1986). Landscape preference and personality. Landscape and Urban Planning, 13(0), 1928. doi:10.1016/0169-2046(86)90004-6

Ardoin, N. M. (2014). Exploring Sense of Place and Environmental Behavior at an Ecoregional Scale in Three Sites. Human Ecology, 42(3), 425-441. doi:10.1007/s10745-014-9652-x

Asghari, F. (2001). Comparison of Children's Characteristics between Patriarchy and Matriarchy Families. (Master of Science), Allame Tabatabaei University, Tehran. Retrieved from http://mtfq2.blogfa.com/post-10.aspx

Augé, M. (1995). Non-places: Introduction to an Anthropology of Supermodernity (J. Howe, Trans.). London, New York: Verso Books.

Baron, R. M., \& Kenny, D. A. (1986). The moderator-mediator variable distinction in social psychological research: Conceptual, strategic, and statistical considerations. Journal of personality and Social Psychology, 51(6), 1173-1182.

Barzegar, M. (1996). Cattell 16 Personality Factor Questionnaire Standardization of 
High School Students in Shiraz (Master), Allame Tabatabaee University, Tehran. Retrieved from http://mhrn.net/rdsm_assayinf.php?slc lan $\mathrm{g}=$ fa\&sid=1\&mod=assayinf_profile\&assa yinf_id=471\&rds_id= Available from Google

Bergum, B. O., \& Cooper, T. (1977). Undergraduate Self-Perceptions of Creativity and Independence. Perceptual and Motor Skills, 44(1), 187-190. doi:10.2466/pms.1977.44.1.187

Buijs, A. E., Elands, B. H. M., \& Langers, F. (2009). No wilderness for immigrants: Cultural differences in images of nature and landscape preferences. Landscape and Urban Planning, 91(3), 113-123. doi:10.1016/j.landurbplan.2008.12.003

Cattell, H. E., \& Mead, A. D. (2008). The sixteen personality factor questionnaire (16PF). In G. J. Boyle, G. Matthews, \& D. H. Saklofske (Eds.), The SAGE handbook of personality theory and assessment (Vol. 2, pp. 135-159 (135-136,138-139,141,144152)). Los Angeles, California, London: SAGE.

Cattell, R. B. (1956). A shortened "Basic English" version (Form C) of the $16 \mathrm{PF}$ Questionnaire. The Journal of Social Psychology, 44(2), 257-278. doi:10.1080/00224545.1956.9921928

Chen, Z., Xu, B., \& Devereux, B. (2016). Assessing public aesthetic preferences towards some urban landscape patterns: the case study of two different geographic groups. Environmental Monitoring \& Assessment, $\quad$ 188(1), 1-17. doi:10.1007/s10661-015-5007-3

Crow, T., Brown, T., \& De Young, R. (2006). The Riverside and Berwyn experience: Contrasts in landscape structure, perceptions of the urban landscape, and their effects on people. Landscape and Urban Planning, 75(3-4), 282-299. doi:10.1016/j.landurbplan.2005.04.002

Dearden, P. (1984). Factors influencing landscape preferences: An empirical investigation. Landscape planning, 11(4), 293-306. doi:http://dx.doi.org/10.1016/03043924(84)90026-1

Egan, S., \& Stelmack, R. M. (2003). A personality profile of Mount Everest climbers. Personality and Individual Differences, 34(8), 1491-1494. doi:http://dx.doi.org/10.1016/S01918869(02)00130-7

Eysenck, H. J. (1990). Biological dimensions of personality. In L. A. Pervin (Ed.), Handbook of personality: Theory and research (pp. 244-276). New York: Guilford Press.

García-Llorente, M., Martín-López, B., IniestaArandia, I., López-Santiago, C. A., Aguilera, P. A., \& Montes, C. (2012). The role of multi-functionality in social preferences toward semi-arid rural landscapes: An ecosystem service approach. Environmental Science \& Policy, 19-20(Supplement C), 136-146. doi:https://doi.org/10.1016/j.envsci.2012.0 1.006

Hanash, K. A. (2008). New Frontiers in Men's Sexual Health: Understanding Erectile Dysfunction and the Revolutionary New Treatments. Connecticut: Greenwood Publishing Group.

Harris Jr., P. M. (2009). Classifying and assessing rural visual landscape quality in Fabius, New York: A psychometric and participation-based approach. (M.S. dissertation), State University of New York College of Environmental Science and Forestry, United States, New York. Retrieved from http://proquest.umi.com/pqdweb/?did=216 $0386351 \&$ sid $=1 \&$ Fmt $=2 \&$ clientId=27905 $\& \mathrm{RQT}=309 \& \mathrm{VName}=\mathrm{PQD} \quad$ Available from ProQuest Dissertations \& Theses: Full Text database. (AAT 1482175)

Hurlock, E. B. (1974). Personality developement. New York: McGraw-Hill.

IRNA (Islamic Republic News Agancy of Isfahan Province) (2010). Why Isfahan is called Half of the World? Available from http://esfahan.irna.ir/fa/News/2000400346 / (accessed April 2015).

Jin, Y., \& Yongyu, G. (2007). The relationship between personality, social support, and subjective well-being. Studies of Psychology and Behavior, 1:013.

Johnson, J. A., \& Feldman, L. A. (2013). Evolution of Personality, Mood, and Landscape Preferences. Paper presented at the Sixth Annual Meeting of the Human Behavior and Evolution Society, Michigan. Justice Ministry of Isfahan. (2008, 13 Mar 2014). Introduction to the Province. Retrieved from http://www.tazirat.gov.ir/esfahan/default6799.aspx

Krejcie, R. V., \& Morgan, D. W. (1970). Determining Sample Size for Research Activities. Educational and Psychological Measurement, 30(3), 607-610. doi:10.1177/001316447003000308

Maciá, A. (1979). Visual perception of landscape: Sex and personality differences. Paper presented at the National Conference on Applied Techniques for 
Analysis and Management of the Visual Resource, Incline Village, Nevada. http://www.fs.fed.us/psw/publications/doc uments/psw_gtr035/psw_gtr035_05_maci a.pdf

Piaget, J. (1964). Part I: Cognitive development in children: Piaget development and learning. Journal of Research in Science Teaching, 2(3), 176-186. doi:10.1002/tea.3660020306

Purcell, T., Peron, E., \& Berto, R. (2001). Why do preferences differ between scene types? Environment and Behavior, 33(1), 93.

Rajabi, P. (2008). Iran at a Glance (A. Vasigh, Trans.). Tehran: Yasavoli.

Relph, E. C. (1976). Place and Placelessness. London: Pion Ltd.

Saif, A. A. (1996). Educational Psychology: Psychology of Learning and Instruction (15 ${ }^{\text {th }}$ ed.). Tehran: Agah Publication.

Schultz, D. P., \& Schultz, S. E. (1994). Theories of personality ( $5^{\text {th }}$ ed.). Belmont, Pacific Grove,California: Books/Cole Publishing Company, Wadsworth, Inc.

Seaward, B. L. (2005). Quiet Mind, Fearless Heart: The Taoist Path through Stress and Spirituality. New Jersey: John Wiley \& Sons, Inc.

Sevenant, M., \& Antrop, M. (2006). Mapping cultural dimensions of the urbanized landscape for a stratified survey of landscape preference: A case study of Ghent, Belgium. Alfa Spectra STU. Planning Studies-Central European Journal of Architecture and Planning FA STU, 10(2), 11.

Sevenant, M., \& Antrop, M. (2010). The use of latent classes to identify individual differences in the importance of landscape dimensions for aesthetic preference. Land Use Policy, 27(3), 827-842. doi:10.1016/j.landusepol.2009.11.002

Short, M. B., \& Rosenthal, S. L. (2003). Adolescent Health. In T. H. Ollendick \& C. S. Schroeder (Eds.), Encyclopedia of Clinical Child and Pediatric Psychology (pp. 17-18). New York: Plenum.

Sonnenfeld, J. (1969). Equivalence and distortion of the perceptual environment.
Environment and Behavior, 1(1), 83-99. doi:10.1177/001391656900100106

Stamps, A. E. (1999). Demographic effects in environmental aesthetics: A meta-analysis. Journal of Planning Literature, 14(2), 155175. doi:10.1177/08854129922092630

Strumse, E. (1996). Demographic differences in the visual preferences for agrarian landscapes in western Norway. Journal of Environmental Psychology, 16(1), 17-31. doi:10.1006/jevp.1996.0002

The Education Department of Isfahan. (2013). Statistical Yearbook of Isfahan State. In S. population (Ed.), Microsoft Word (Vol. 29.0 KB). Isfahan: Education Department of Isfahan.

Van den Berg, A. E., \& Koole, S. L. (2006). New wilderness in the Netherlands: An investigation of visual preferences for nature development landscapes. Landscape and Urban Planning, 78(4), 362-372. doi:10.1016/j.landurbplan.2005.11.006

Van den Berg, A. E., Vlek, C. A. J., \& Coeterier, J. F. (1998). Group differences in the aesthetic evaluation of nature development plans: A multilevel approach. Journal of Environmental Psychology, 18(2), 141157. doi:10.1006/jevp.1998.0080

Winkel, G. H., Malek, R., \& Thiel, P. (1969). The role of personality differences in judgments of roadside quality. Environment and Behavior, 1(2), 199-223. doi:10.1177/001391656900100205

$\mathrm{Yu}$, K. (1995). Cultural variations in landscape preference: Comparisons among Chinese sub-groups and Western design experts. Landscape and Urban Planning, 32(2), 107-126. doi:10.1016/01692046(94)00188-9

Zheng, B., Zhang, Y., \& Chen, J. (2011). Preference to home landscape: wildness or neatness? Landscape and Urban Planning, 99(1), 1-8.

Zube, E. H., Pitt, D. G., \& Evans, G. W. (1983). A lifespan developmental study of landscape assessment. Journal of Environmental Psychology, 3(2), 115-128. doi: $\quad$ http://dx.doi.org/10.1016/S02724944(05)80151-3 